\title{
Alternate Systems of Health in India
}

\section{Singh $\mathbf{A}^{1}$ and Siddiqui $\mathrm{AM}^{2 *}$}

${ }^{1}$ Professor \& Head of Department, The Department of Community Medicine, Rohilkhand Medical College \& Hospital, Bareilly International University, India ${ }^{2}$ Professor and HOD, Department of Community Medicine, Government Medical College, India

\section{Mini Review}

Volume 3 Issue 3

Received Date: September 07, 2019

Published Date: November 08, 2019

DOI: $10.23880 /$ eij-16000130

*Corresponding author: Arshiya Masood Siddiqui, Professor and HOD, Department of Community Medicine, Government Medical College, Orai, Jalaun, Uttar Pradesh, PIN-285001, India, Tel: +91-9412277491; Email: arshiyamasood123@gmail.com

\section{Abstract}

Currently the health care system of whole world is dependent on allopathic system of medicine and surgery. This status of allopathic system didn't come overnight. It has taken hundreds of years in its evolvement. In the past many systems of medicine existed and cured the global people. Although many systems developed and evolved in the restricted geographical areas and served the people but we cannot ignore the contributions of these regional systems of many past civilizations in the development of current and modern system of allopathic medicine and surgery. This review is basically intended to highlight the various millstones in the evolution of modern system. It will also highlight the contributions of many systems of cure and prevention of diseases form many parts/continents/countries of the world. It is the primary effort of this review to identify the milestones in the development of modern system and contributions of many civilizations in the health sector. The ancient systems of treatment from all the parts of world can play important role as supplementary system of treatment and can reduce the cost of treatment, save time as these are more accessible and more popular locally. For example recently the Government of India and people of India have recognized the role of AYUSH i.e. Ayurveda, Yoga and Naturopathy, Unani, Siddha, Sowa-Rigpa and Homeopathy as the alternative systems of medicine. It is integrated in the health care delivery system of the country. Although India has rich heritage of health care system form ancient times yet has never hesitated in taking the help form foreign countries and civilizations for the better health conditions of its people. We recently utilised the knowledge of Chinese medicine e.g. acupuncture, acupressure and we have taken help from Greek medicine also.

Keywords: AYUSH; Chinese medicine; Allopathic system; Alternative Medicine

\section{Introduction}

Alternative systems of health include various healing approaches that originated from around the world and that are not based on conventional western system of medicine. These therapies are called alternative systems of health and are used alone or as complementary systems of medicine used with conventional system of western medicine [1]. The National Planning Committee chaired by the first Prime Minister of India and it had representatives from the government as well. The National Health sub Committee 
was chaired by Col. S S Sokhey, This Committee was appointed in 1938 and began its work early in 1939 . Due to arrest of chairman of parent Committee, the work got impacted and finally the report was submitted in 1947 [2]. Among various recommendations one important recommendation was mainstreaming the indigenous practitioners of medicine. Since then, from time to time various Committees, Planning Commissions (Five Year Plans) and now NITI Ayog (2015) have realized that without the mainstreaming of practitioners of Indigenous/Alternate system of Medicine, the humongous health problem of the country can't be solved. National Rural Health Mission (NRHM) launched in 2005 now National Health Mission (NHM) since 2013 also laid emphasis on mainstreaming AYUSH (Ayurveda, Yoga, Unani, Siddha \& Homeopathy). Much is talked about mainstreaming. What constitutes the mainstream? [3].

"Mainstreaming takes the historical specialty like history of medicine, lift it out of confining limits of disciplinary channel and refloats in broader historical current. Doing so require us to write medical history in new ways" [4].

Irfan Habib, the great historian of India says

"Medical science like any other branch of knowledge has in its history tended to develop its own sets assumptions (superstitions) and accumulations of experience. Such of these as have remained confined to particular regions or cultures, have tended to grow into 'classical systems' of which Ayurveda and Yunani (Graeco-Arab) systems are two obvious examples" [5].

Like these several other systems of Alternate Medicine are prevalent in India e.g. Homeopathy, Traditional Chinese Medicine (TCM), Sowa rigpa etc. It is well known that health is a social construct which is deeply embedded in culture. So it becomes important to focus on these systems and do systematic research and incorporates what is scientific and evidence based in these systems [6].

\section{Alternate Health Systems' Approaches}

Holism: The idea that whole of the sick person including their body mind and way of the life should be considered when treating them and not just the symptom of the disease $[7,8]$.

Humanism: A system that thought consider the solving of human problems with the help of religious belief it emphasizes that fact the basic nature of human is good $[9,10]$.

\section{Types of Use of Available Health Systems}

Conventional System of Western Medicine: Allopathic system of medicine and surgery currently most popular and constitutes mainstream of health system worldwide.

Complementary Medicine: Used together with conventional medicine for example, using massage therapy along with prescription medicine to treat anxiety [11].

Alternative Medicine: Traditionally used in place of conventional medicine however, as alternative medicine has gained scientific creditability, they are used along with conventional treatment. Complementary and Alternative Medicine (CAM) practices are becoming more accepted as mainstream generally incorporates a holistic approach, focusing on treating the whole body and the mind, used widely throughout the world $[12,13]$.

\section{Alternative Systems of Health in India}

Ayurveda (Ayurvedic Medicine): Began thousands of years ago in India, Aims to restore harmony by questioning, observing, touching, and classifying patients $[14,15]$.

Homeopathy: Unconventional Western system based on the idea that "like cures like" Herbal medicine, minerals, and chemicals in diluted forms to kill or ward off illness.

Traditional Chinese Medicine (TCM): Emphasizes the proper balance of qi (pronounced "chi"), Acupuncture, herbal medicine, massage, and qigong. Bare-foot doctors are excellently working and successful in China. They are backbone of the health care delivery system of china.

Sowa-Rigpa: The Tibetan System of Medicine is practiced in Tibet, Nepal, Bhutan, India. Therapies are almost similar with Ayurveda and Chinese Medicine

\section{Important Medicine in the World}
1. Ayurvedic Medicine [16,17]
2. Allopathic Medicine
3. Egyptian Medicine
4. Mesopotamian Medicine
5. Greek Medicine
6. Roman Medicine
7. Chinese Medicine
8. The Tibetan System of Medicine

The Following Distinct Patterns Observed among those who Use more CAM: More women than men, people with levels of higher education, those hospitalized within the past year, former smokers, people with back, neck, head, and joint pain or other such conditions, those with gastrointestinal disorders or sleeping problems $[18,19]$.

Traditional medicine [20] (also known as indigenous or folk medicine) and the World Health Organization (WHO) defines traditional medicine as "the sum total of the knowledge, skills, and practices 
based on the theories, beliefs, and experiences indigenous to different cultures, whether explicable or not, used in the maintenance of health as well as in the prevention, diagnosis, improvement or treatment of physical and mental illness" [21].

Indigenous Systems of Medicines in India are Ayurveda, Yoga-Naturopathy, Unani, Siddha, Homeopathy (AYUSH) among these the Ayurveda, YogaNaturopathy and Siddha originated in India. Along with the Allopathic or Western system of Medicine the system of medicines which are considered to be Indian in origin i.e. Ayurveda, Yoga-Naturopathy, Siddha or the systems of medicine, which have come to India from outside i.e. Unani and Homeopathy got assimilated in to Indian culture are known as Indian Systems of Medicine [21].

The word 'Ayurveda' comes from the Sanskrit word 'ayur' meaning 'life' and 'veda' meaning 'to know'. Ayurveda means 'the science of life', and is a medical system practiced in India, Sri Lanka and Nepal. The Ayurveda is considered the 'upaveda' or accessory Veda to the Atharva Veda, which is the first Hindu text on medicine and is the fourth book of the Vedas [17]. The concept of Ayurvedic treatment began approximately five thousands of years ago in India. It aims to restore harmony by questioning, observing, touching, and classifying patients. It is practiced in whole India. It has been nourished promoted and advocated since its origin by Dhanvantari, Atreya, Charak, Susruta, Vaghbatta. Ayurvedic text books started by Dhanvantari, Atreya, Charak, Susruta, Vaghbatta. The Charak Sammhita and Susruta Samhita, contributed to modern medicine. Susruta mentions eight branches in Ayurveda - General medicine, Surgery-plastic surgery, ENT and Eye diseases, Toxicology, Psychiatry, Pediatrics, Gynecology, Sexology and Virility [22].

Role of Charak in Ayurveda is very important [23]: Charak written more than 500 drugs in Charak Samhita. He used reserpine for treating hypertension obtained from rauwolfia plant

Role of Susruta in Ayurveda is very important [24]: $\mathrm{He}$ is the father of Indian surgery, He has written Susruta Samhita and worked on cataract extraction, hernia repairing operations, amputations, tumours excision and contributed in Anatomy, medicine, Midwifery, Ophthalmology, Pathology, Hygiene

Siddha System: Practiced in south India

The 10 Most Common CAM Therapies among Adults Complementary and Alternative Medicine (CAM)

1. Natural herbal products $(17.7 \%)$

2. Deep Breathing (12.7\%)

3. Meditation (9.4\%)

4. Chiropractic and osteopathic $(8.6 \%)$
5. Massage (8.3\%)

6. Yoga $(6.1 \%)$

7. Diet Based therapies (3.6\%)

8. Progressive relaxation $(2.9 \%)$

9. Guided imagery $(2.2 \%)$

10. Homeopathic treatment $(1.8 \%)[25,26]$

Much is said and little is done. A wide gap exists between rhetoric and reality. Political will is vital to translate the knowledge into action. Now the time has come to lift these systems out of confining limits of disciplinary Channels and refloat it into broader historical current that means the write the history in new ways. The National Medical Commission Bill 2019 proposes to give limited license to the practitioners of these systems to practice medicine (National Medical Commission Bill, 2019) after training, programming and defining their roles and responsibilities. Their services will go a long way in providing primary health care in the country.

\section{References}

1. Tabish SA (2008) Complementary and alternative healthcare: Is it evidence-based? Int J Health Sci (Qassim) 2(1): 5-9.

2. Gupta RP (2017) Health Care Reforms in India. $1^{\text {st }}$ (Edn.), Elsevier, pp: 466.

3. Shankar D, Patwardhan B (2017) AYUSH for new India: vision and strategy. J Ayurveda Integr Med 8(3): 137-139.

4. Mary L (1999) Medicine and Society in Early Europe. Cambridge, pp: 1.

5. Habib I (2012) Inside and Outside the System. In: Deepak Kumar (Ed.), Diseases and Medicine in India, A Historical Overview. Indian History Congress, Tulika Books, pp: 71.

6. Patwardhan B, Warude D, Pushpangadan P, Bhatt N (2005) Ayurveda and traditional Chinese medicine: a comparative overview. Evid Based Complement Alternat Med 2(4): 465-473.

7. Kunitz SJ (2002) Holism and the idea of general susceptibility to disease. Int J Epidemiol 31(4): 722729.

8. Holism.

9. Lee Roze des Ordons A, de Groot JM, Rosenal T, Viceer N, Nixon L (2018) How clinicians integrate humanism in their clinical workplace-'Just trying to put myself in their human being shoes. Perspect Med Educ 7(5): 318-324. 


\section{Epidemiology International Journal}

10. American Humanist.

11. Spiegel D, Stroud P, Fyfe A (1998) Complementary medicine. West J Med 168(4): 241-247.

12. Institute of Medicine (2005) (US) Committee on the Use of Complementary and Alternative Medicine by the American Public. Complementary and Alternative Medicine in the United States. Washington (DC): National Academies Press (US).

13. Anlauf M, Hein L, Hense HW, Köbberling J, Lasek R, et al. (2015) Complementary and alternative drug therapy versus science-oriented medicine. Ger Med Sci 13: Doc05.

14. Rudra S, Kalra A, Kumar A, Joe W (2017) Utilization of alternative systems of medicine as health care services in India: Evidence on AYUSH care from NSS 2014. PLoS One 12(5): e0176916.

15. Ravishankar B, Shukla VJ (2007) Indian systems of medicine: a brief profile. Afr J Tradit Complement Altern Med 4(3): 319-337.

16. Pan SY, Litscher G, Gao SH, Zhou SF, Yu ZL, et al. (2014) Historical perspective of traditional indigenous medical practices: the current renaissance and conservation of herbal resources. Evid Based Complement Alternat Med 2014: 20.

17. Zuskin E, Lipozencic J, Pucarin-Cvetkovic J, Mustajbegovic J, Schachter N, et al. (2008) Ancient medicine--a review. Acta Dermatovenerol Croat 16(3): 149-157.
18. Hori S, Mihaylov I, Vasconcelos JC, McCoubrie M (2008) Patterns of complementary and alternative medicine use amongst outpatients in Tokyo, Japan. BMC Complement Altern Med 8: 14.

19. Yuan H, Ma Q, Ye L, Piao G (2016) The Traditional Medicine and Modern Medicine from Natural Products. Molecules 21(5): 559.

20. Prasad LV (2002) Indian System of Medicine and Homoeopathy. Ranjit Roy C, Uton Muchatar R (Ed.), Traditional Medicine in Asia. WHO- Regional Office for South East Asia, New Delhi, pp: 283-286.

21. Galib, Barve M, Mashru M, Jagtap C, Patgiri BJ, et al. (2011) Therapeutic potentials of metals in ancient India: A review through Charaka Samhita. J Ayurveda Integr Med 2(2): 55-63.

22. Singh V (2017) Sushruta: The father of surgery. Natl J Maxillofac Surg 8(1): 1-3.

23. Johnson PJ, Kozhimannil KB, Jou J, Ghildayal N, Rockwood TH (2016) Complementary and Alternative Medicine Use among Women of Reproductive Age in the United States. Womens Health Issues 26(1): 40-47.

24. Judson PL, Abdallah R, Xiong Y, Ebbert J, Lancaster JM (2017) Complementary and Alternative Medicine Use in Individuals Presenting for Care at a Comprehensive Cancer Center. Integr Cancer Ther 16(1): 96-103. 